\title{
Is Abdominal Computed Tomography Helpful for the Management of an Intestinal Obstruction Caused by
} a Bezoar?

\author{
Byung-Kwon Ahn \\ Department of Surgery, Kosin University College of Medicine, Busan, Korea
}

\section{See Article on Page 89-93}

Bezoars can be defined as retained concretions of animal or vegetable material in the gastrointestinal tract. Bezoars are classified according to their composition into phytobezoars (undigested vegetables), trichobezoars (hairs), lactobezoars (milk) and pharmacobezoars (medications) [1]. Phytobezoars are composed of undigested food fibers, such as cellulose, hemicellulose, lignin and fruit tannin. These fibers occur in fruits and vegetables such as celery, pumpkins, prunes, raisins, leeks, beets and persimmons. Especially, ingestion of persimmons is known to be a common cause of bezoars. Persimmon bezoars are also known as diospyrobezoars. In 1986, Krausz et al. [2] reported that $91.2 \%$ of 113 patients with phytobezoars had a history of persimmon intake. Kement et al. [3] also reported that excessive consumption of persimmons was identified in $40.5 \%$ of bezoar patients. Unripe persimmons contain soluble tannin. Tannin polymerizes in an acidic environment to form a glue-like coagulum, which can affix to other materials in the stomach [4].

A number of predisposing factors may contribute to the risk of bezoar formation. Previous gastric surgery was reported in 20 to $93 \%$ of patients with bezoars $[2,5-8]$. In this paper, the authors reported that $35 \%$ (7 patients) of patients had had previous gastric surgery. The other predisposing factors observed in our study included mastication problems, diabetic gastroparesis and antacid drug use.

Bezoars usually form in the stomach and can pass into the small bowel where they occasionally cause obstruction. Although be-

\section{Correspondence to: Byung-Kwon Ahn}

Department of Surgery, Kosin University College of Medicine, 262

Gamcheon-ro, Seo-gu, Busan 602-702, Korea

Tel: +82-51-990-6299, Fax: +82-51-246-6093

E-mail:gsabk@hotmail.com zoars are the most common type of foreign body lodged in any part of the gastrointestinal tract, the overall incidence of bezoarinduced intestinal obstruction remains relatively low. Incidence of intestinal obstruction caused by bezoars is 2 to $4 \%$ [9].

The differential diagnosis of intestinal obstruction secondary to bezoars is difficult before surgery because the clinical and the radiographic findings are similar to those of intestinal obstruction attributable to other causes. However, findings from recent studies suggest that sonography or computed tomography (CT) can be useful in diagnosing bezoars before surgery $[6,10]$. CT scans demonstrate a well-defined round, heterogeneous intraluminal mass in the gastrointestinal tract. The mass can be outlined by the bowel wall and presents a characteristic internal gas bubble-soft tissue appearance [11-14]. Kement et al. [3] reported that abdominal CT was carried out in 16 patients and that bezoars were revealed in $14(77.7 \%)$ of those patients before surgery. In this paper, the accuracy of abdominal CT in diagnosing bezoars was $47 \%$ ( 7 of 15 patients). The authors compared the clinical courses of three groups, patients who were preoperatively diagnosed with bezoars by using abdominal CT (group 3), patients who were not diagnosed using abdominal CT (group 2), and patients who did not undergo abdominal CT (group 1). In the group 3, because of the abdominal CT earlier surgery was possible ( 0.6 days vs. 4.9 days, $\mathrm{P}=0.036$ ), and the incidence of postoperative complications was lower $(14.3 \%$ vs. $37.5 \%, 40 \%, \mathrm{P}=0.439)$. However, as the authors addressed, there are some limitations in this study. The hospital stay was little longer in group 3 than group 2, and heterogeneity of the patients' clinical courses is expected.

In patients with intestinal obstructions, differential diagnosis is very important, especially in patients with a history of previous abdominal surgery. CT can help to make this differentiation. Therefore, CT should be performed whenever possible in all patients with bowel obstruction to establish the diagnosis and to avoid inappropriate treatment.

\section{REFERENCES}

1. Andrus CH, Ponsky JL. Bezoars: classification, pathophysiology, 
and treatment. Am J Gastroenterol 1988;83:476-8.

2. Krausz MM, Moriel EZ, Ayalon A, Pode D, Durst AL. Surgical aspects of gastrointestinal persimmon phytobezoar treatment. Am J Surg 1986;152:526-30.

3. Kement M, Ozlem N, Colak E, Kesmer S, Gezen C, Vural S. Synergistic effect of multiple predisposing risk factors on the development of bezoars. World J Gastroenterol 2012;18:960-4.

4. Verstandig AG, Klin B, Bloom RA, Hadas I, Libson E. Small bowel phytobezoars: detection with radiography. Radiology 1989;172: 705-7.

5. Gaya J, Barranco L, Llompart A, Reyes J, Obrador A. Persimmon bezoars: a successful combined therapy. Gastrointest Endosc 2002; 55:581-3.

6. Ripolles T, Garcia-Aguayo J, Mart L, Llompart A. Gastrointestinal bezoars: sonographic and CT characteristics. AJR Am J Roentgenol 2001;177:65-9.

7. Buchholz RR, Haisten AS. Phytobezoars following gastric surgery for duodenal ulcer. Surg Clin North Am 1972;52:341-52.

8. Bowden TA Jr, Hooks VH 3rd, Mansberger AR Jr. The stomach after surgery. An endoscopic perspective. Ann Surg 1983;197: $637-44$.
9. Bedioui H, Daghfous A, Ayadi M, Noomen R, Chebbi F, Rebai W, et al. A report of 15 cases of small-bowel obstruction secondary to phytobezoars: predisposing factors and diagnostic difficulties. Gastroenterol Clin Biol 2008;32:596-600.

10. Gayer G, Jonas T, Apter S, Zissin R, Katz M, Katz R, et al. Bezoars in the stomach and small bowel--CT appearance. Clin Radiol 1999; 54:228-32.

11. Kim JH, Ha HK, Sohn MJ, Kim AY, Kim TK, Kim PN, et al. CT findings of phytobezoar associated with small bowel obstruction. Eur Radiol 2003;13:299-304.

12. Quiroga S, Alvarez-Castells A, Sebastia MC, Pallisa E, Barluenga E. Small bowel obstruction secondary to bezoar: CT diagnosis. Abdom Imaging 1997;22:315-7.

13. Frager D, Medwid SW, Baer JW, Mollinelli B, Friedman M. CT of small-bowel obstruction: value in establishing the diagnosis and determining the degree and cause. AJR Am J Roentgenol 1994; 162:37-41.

14. Fukuya T, Hawes DR, Lu CC, Chang PJ, Barloon TJ. CT diagnosis of small-bowel obstruction: efficacy in 60 patients. AJR Am J Roentgenol 1992;158:765-9. 